\section{Pharmacological actions of FGF19 and FGF21 revealed}

The mechanisms that underlie the pharmacological effects of fibroblast growth factor 19 (FGF19), FGF21 and FGF mimetic antibodies are not well understood. Now, David Mangelsdorf, Steven Kliewer and colleagues report that FGF21, FGF19 and bFKB1, a humanized FGFR1/ $\beta$ klotho-activating antibody, must act on the nervous system to cause the beneficial pharmacological effects on weight loss and glycaemia.

FGF19 and FGF21 act through cell-surface receptors comprised of FGF receptors in complex with $\beta$-klotho, a transmembrane protein. The authors used mice with specific knockout of $\beta$-klotho in to disable the actions of both FGFs and bFKB1 in target tissues. This approach enabled the investigators to demonstrate where in the body the molecules have their physiological and pharmacological effects, as well as the relative importance of the liver, adipose tissue and nervous system in mediating the long-term metabolic actions of all three compounds. hepatocytes, adipocytes or neurons
The authors showed that $\beta$-klotho expression in the nervous system, but not in the liver or adipose tissue, is required for the pharmacological effects of FGF19, FGF21 and bFKB1 on weight loss and glycaemia. This finding was surprising because until now researchers had assumed that each of the molecules have different sites of action in peripheral tissues. Perhaps the biggest surprise, however, was that the nervous system was the site of action for the mimetic antibody bFKB1 - Mangelsdorf and colleagues are the first to show that bFKB1 can cross the blood-brain barrier. Mangelsdorf and colleagues also showed that FGF21 has almost no direct activity in the liver. FGF21 did have notable effects on liver metabolism, but these were mediated by its action in other tissues, particularly the nervous system.

"Our findings demonstrate that drugs that target the anti-obesity and metabolic effects of FGF19 and FGF21 (including antibodies) will need to be able to access the nervous system to be effective," concludes Mangelsdorf. "Given the great pharmacological interest in FGF19 and FGF21, these findings are likely to change the current direction of future research in this area."

Alan Morris

ORIGINAL ARTICLE Lan, T. et al. FGF19, FGF21, and an FGFR1/ $\beta$-Klotho-activating antibody act on the nervous system to regulate body weight and glycemia. Cell Metab. http://dx.doi. org/10.1016/j.cmet.2017.09.005 (2017)

\section{...these}

findings are

likely to change

the current

direction of

future research

in this area

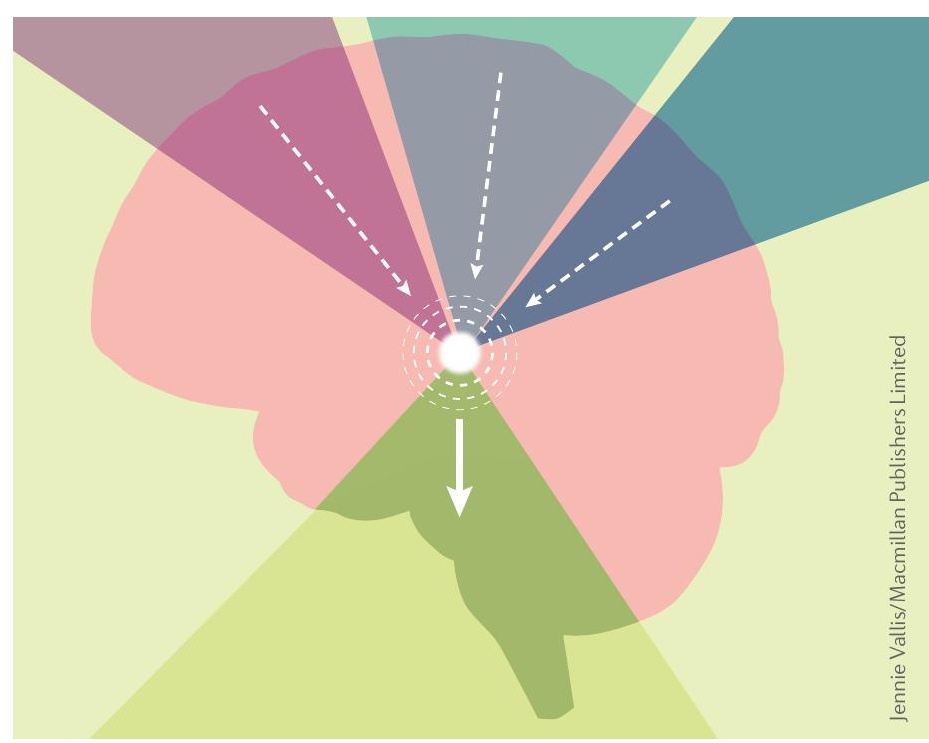

